\title{
Adsorption of U(VI) in Solution by Biochar and FeS Nanoparticles
}

\author{
Xitong Zheng, Long Fu, Hao Deng, Keyuan Huang, Tianqi Liu, Yulin Deng, Jiaming Luo, Miao Xiang, \\ Anjie Wang, Muqing Qiu, Li Han and Hai Wang $\dagger$ \\ School of Life Science, Shaoxing University, Huancheng West Road 508, Shaoxing, 312000, P. R. China \\ †Corresponding author: Hai Wang; wanghai@usx.edu.cn
}

Nat. Env. \& Poll. Tech.

Website: www.neptjournal.com

Received: 15-06-2020

Revised: $06-10-2020$

Accepted: 09-10-2020

Key Words:

Adsorption

$\mathrm{U}(\mathrm{VI})$

Biochar

FeS

\begin{abstract}
Uranium $(U)$ is a common radionuclide in soil and groundwater. Uranium contamination often results from uranium mining and processing, nuclear energy power plants, nuclear weapon tests and nuclear accidents. Due to its toxicity and bioaccumulation, it was necessary to treat it effectively. Biochar and FeS nanoparticles were prepared for the treatment of $\mathrm{U}(\mathrm{VI})$ in solution. The characteristics of biochar and FeS nanoparticles were determined by Scanning Electron Microscopy, Energy Dispersive Spectrum and Fourier Transform Infrared Spectroscopy and BET adsorption method. The results showed that a large number of functional groups were present on the surface of biochar and FeS nanoparticles. The influencing factors, such as contact time, $\mathrm{pH}$ of the solution, initial concentration $\mathrm{U}(\mathrm{VI})$ and solution temperature, had an important influence on the adsorption capacity of $\mathrm{U}(\mathrm{VI})$ by biochar and FeS nanoparticles.
\end{abstract} .

\section{INTRODUCTION}

The development of new energy has become a requirement for sustainable economic development and national defence construction. As a green energy source, nuclear energy has attracted extensive attention from countries around the world (Liu et al. 2010, Vogel et al. 2010). Among them, uranium as the main nuclear fuel needs to increase its development and smelting efforts. However, a large amount of uranium wastewater will be generated during the development, smelting and use of uranium. The direct discharge of uranium wastewater will cause water and soil pollution causing serious harm to the environment and humans (Lovering et al. 2016, Veliscek-Carolan 2016). Therefore, the treatment of uranium wastewater is urgent. The treatment of uranium wastewater usually adopts coagulation-filtration method, evaporation-concentration method, ion exchange method, biological method, adsorption method, etc. (Li et al. 2012). The coagulation-filtration method is a simple process and low cost. However, the concentration of uranium in the effluent of the wastewater treated by this method is relatively high and needs further treatment. The evaporative concentration method is simple, effective and has a high removal rate and high cost. The ion exchange method has good removal rate and low concentration of uranium in the effluent. However, the treatment cost is high, and it is easy to bring secondary pollution. The biological method has a high removal rate, but its practical application is difficult. Adsorption method is a simple and efficient wastewater treatment method. In recent years, it has been widely used in the treatment of wastewater containing uranium (Feng et al. 2016, Sun et al. 2016, Li et al. 2019, Ma et al. 2019).

At present, the commonly used adsorbents are montmorillonite, kaolin, chitosan, graphene, nano-zero iron, biochar, etc. (Li et al. 2012, Decker et al. 2017, Qiu \& Huang 2017). Biochar has become the main application and research adsorbent for pollutant removal in the water environment due to its wide source, economical and environmental protection (Jin et al. 2018). FeS nanoparticles are effective fixatives for the removal of heavy metals with low solubility of metal sulphide (Liu et al. 2008). FeS is a natural sulphide mineral and an excellent fixative for heavy metals for its unique molecular structure, compositions, and surface chemical properties (Maxim et al. 2007, Milad et al. 2018). Heavy metals can be immobilized by FeS through adsorption, ion exchange, and/or chemical precipitation of highly insoluble metal sulphides (Feng et al. 2008). Numerous studies have reported on the remediation of heavy metal contaminated water prepared in the laboratory by FeS (Hua \& Deng 2008, Hyun et al. 2012, Lyu et al. 2017).

In this study, biochar and FeS nanoparticles were prepared. The characteristic of biochar and FeS nanoparticles are discussed. Adsorption experiments are carried out. The effect of the operational parameters (such as contact time, initial concentration of $\mathrm{U}(\mathrm{VI}), \mathrm{pH}$ in solution and temperature) on 
adsorption capacity by biochar and FeS nanoparticles were evaluated in details.

\section{MATERIALS AND METHODS}

\section{Materials}

Peanut shell was obtained from a farm in the city of Jinan, Shandong province, P.R. China. It was washed three times with water, then dried at $105^{\circ} \mathrm{C}$ for $24 \mathrm{~h}$, and then milled into powder of $2 \mathrm{~mm}$ as the feedstock biomass for biochar production. Ten grams of peanut shell powder was pyrolyzed in a porcelain crucible under the oxygen-limited conditions at $450^{\circ} \mathrm{C}$ for $2 \mathrm{~h}$ in a muffle furnace. The biochar from peanut shell was obtained.

FeS nanoparticles were prepared through co-precipitation of $\mathrm{Na}_{2} \mathrm{~S} .9 \mathrm{H}_{2} \mathrm{O}$ and $\mathrm{FeSO}_{4} \cdot 7 \mathrm{H}_{2} \mathrm{O}$ in the aqueous phase under anoxic conditions (Equation 1).

$$
\mathrm{FeSO}_{4}+\mathrm{Na}_{2} \mathrm{~S} \rightarrow \mathrm{FeS}(\mathrm{s})+\mathrm{Na}_{2} \mathrm{SO}_{4}
$$

All chemicals used in this study were of analytical grade. Sodium sulphide nonahydrate, iron sulphate heptahydrate, $\mathrm{NaOH}, \mathrm{H}_{2} \mathrm{SO}_{4}$, uranium nitrate hexahydrate $\left(\mathrm{UO}_{2} \mathrm{NO}_{3} \cdot 6 \mathrm{H}_{2} \mathrm{O}\right)$ were obtained from Fengchuan Chemical Technology Co. Ltd. (Tianjin, China).

\section{Adsorption Experiments}

Adsorption experiments were carried out on a shaker at 200 rpm under a constant temperature condition. Typically, an amount of the adsorbent was added into $100 \mathrm{~mL} \mathrm{U(VI)} \mathrm{of}$ initial concentration in a $250 \mathrm{~mL}$ Erlenmeyer flask. Flask was sealed by a bottle cap and placed in the shaker at 200 rpm and constant temperature. The anaerobic deionized water was used in adsorption experiments. The $\mathrm{pH}$ in the solution was adjusted by $0.1 \mathrm{~mol} / \mathrm{L} \mathrm{HCl}$ or $\mathrm{NaOH}$ solution. The entire adsorption process reached equilibrium and the supernatant was collected after filtration. The residual sample was centrifuged at $4000 \mathrm{rpm}$ for $5 \mathrm{~min}$. All the experiments were carried out in duplicate and the data were analysed by the mean and standard deviation.

\section{Analytical Methods}

The U(VI) concentration in the supernatant was analysed by UV-vis spectrophotometry. The characteristics of biochar and FeS nanoparticles were determined by Scanning Electron Microscopy (SEM), Energy Dispersive Spectrum (EDS) and Fourier Transform Infrared Spectroscopy (FT-IR), respectively. The specific surface area, pore size and pore volume of biochar and $\mathrm{FeS}$ nanoparticles were determined by the BET adsorption method. The amount of adsorption was calculated using the following formula:

$$
q_{e}=\frac{\left(C_{0}-C_{e}\right) V}{m}
$$

Where, $q_{e}(\mathrm{mg} / \mathrm{g})$ is the amount of adsorption per unit mass of adsorbent at the end of adsorption. $C_{0}(\mathrm{mg} / \mathrm{L})$ and $C_{e}(\mathrm{mg} / \mathrm{L})$ are the initial concentration of the adsorbate in the solution and the concentration at the equilibrium of adsorption. $V(\mathrm{~mL})$ is the volume of solution and $m(\mathrm{~g})$ is the dosage of the modified biochar.

\section{RESULTS AND DISCUSSION}

\section{Characterization of Biochar and FeS Nanoparticles}

SEM images of biochar and FeS nanoparticles were determined by SEM. As shown in Fig. 1A, the morphology of biochar was smooth and a few small fragments were present. While the surface of FeS was compact and aporate (Fig. 1B). The shape was cotton wool. The surface area of biochar $\left(52.17 \mathrm{~m}^{2} / \mathrm{g}\right)$ was greater than that of FeS nanoparticles $\left(18.25 \mathrm{~m}^{2} / \mathrm{g}\right)$. Some related researches have proved that surface area had an important role in the adsorption capacity.

From Fig. 2A, it could be concluded that biochar included a large number of elements, such as $\mathrm{C}, \mathrm{O}, \mathrm{Si}, \mathrm{Mg}$, $\mathrm{K}$ and $\mathrm{Ca}$. Among them, elements of $\mathrm{C}$ and $\mathrm{O}$ for biochar

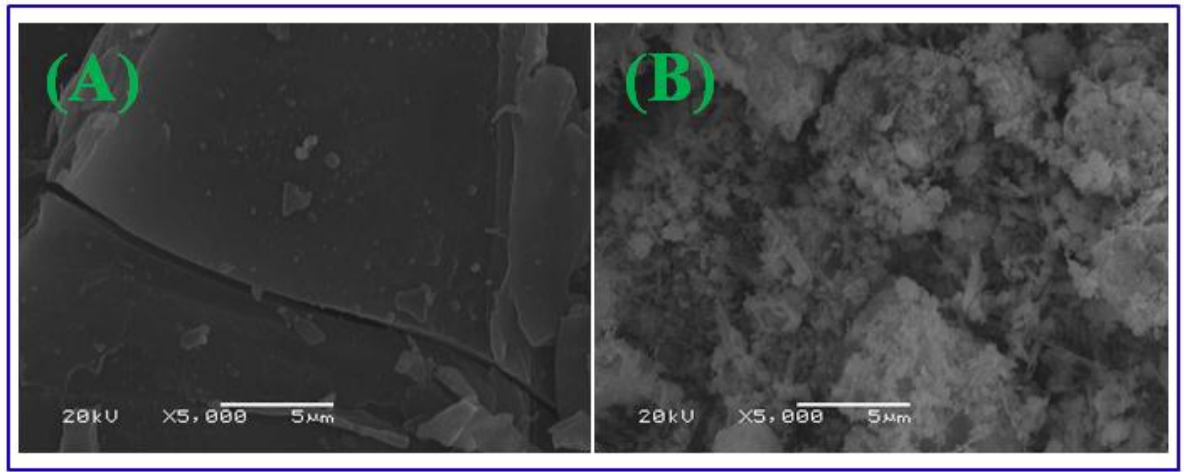

Fig. 1: SEM images of biochar (A) and FeS nanoparticles (B). 


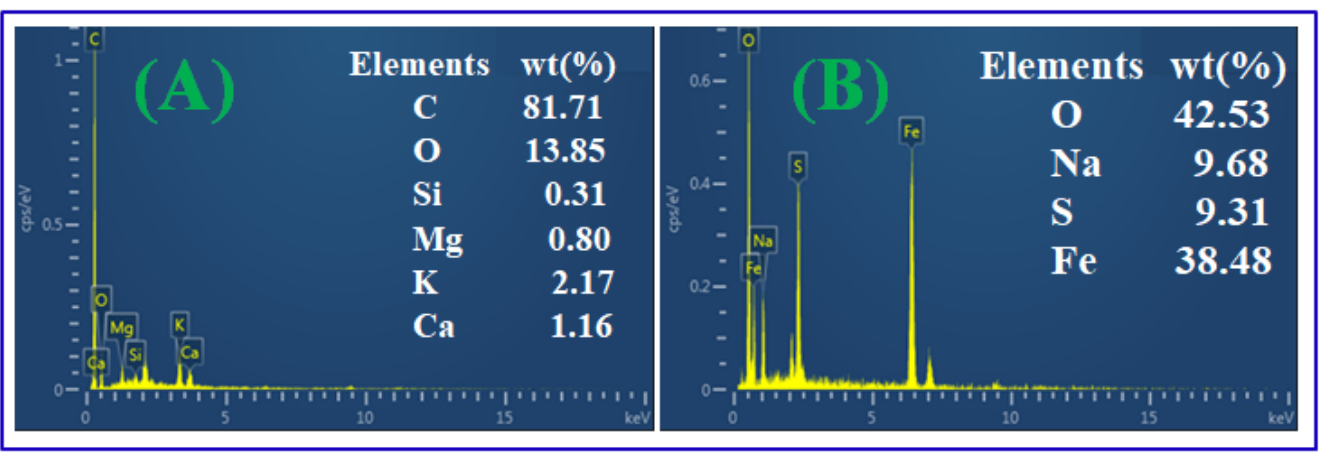

Fig. 2: EDS spectrum of biochar (A) and FeS nanoparticles (B).

were the main elements. Their weights were $81.71 \%$ and $13.85 \%$, respectively. The weights of $\mathrm{Si}, \mathrm{Mg}, \mathrm{K}$ and $\mathrm{Ca}$ were $0.31 \%, 0.80 \%, 2.17 \%$ and $1.16 \%$, respectively. For $\mathrm{FeS}$ nanoparticles (Fig. 2B), elements of $\mathrm{O}, \mathrm{Na}, \mathrm{S}$ and $\mathrm{Fe}$ were observed. Their weights were $42.53 \%, 9.68 \%, 9.31 \%$ and $38.48 \%$, respectively. The elements of $\mathrm{O}$ and $\mathrm{Fe}$ were the main elements.

Fig. 3 displayed the characteristic stretching frequencies of biochar and FeS nanoparticles. Six peaks were observed for biochar at 3363, 2021, 1608, 1379, 1061 and $571 \mathrm{~cm}^{-}$ ${ }^{1}$, respectively. They were attributed to the vibrations of $-\mathrm{OH}, \mathrm{C}-\mathrm{C}, \mathrm{C}=\mathrm{C}, \mathrm{O}=\mathrm{C}-\mathrm{O}, \mathrm{C}-\mathrm{O}$ and $\mathrm{Si}-\mathrm{O}$ functional groups. These functional groups benefited for the adsorption of U(VI). For biochar, possible removal mechanisms consisted of electrostatic attraction and surface complexation (Ahmad et al. 2014). For FeS nanoparticles, four peaks were appeared at 3373, 1601, 1375 and $1074 \mathrm{~cm}^{-1}$, respectively. They were attributed to $-\mathrm{OH}, \mathrm{O}=\mathrm{C}-\mathrm{O}$ and $\mathrm{C}-\mathrm{O}$ functional groups.

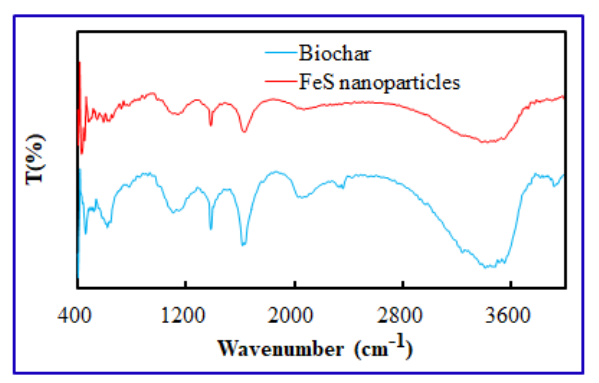

Fig. 3: FT-IR spectrum of biochar and FeS nanoparticles.

\section{Adsorption Experiments}

Adsorption experiments were carried out on a shaker at 200 rpm under a constant temperature condition. The effect of operation parameters (such as $\mathrm{pH}$, contact time, initial concentration U(VI) and temperature) on adsorption capacity by biochar and FeS nanoparticles were tested. The experimental results are shown in Fig. 4.
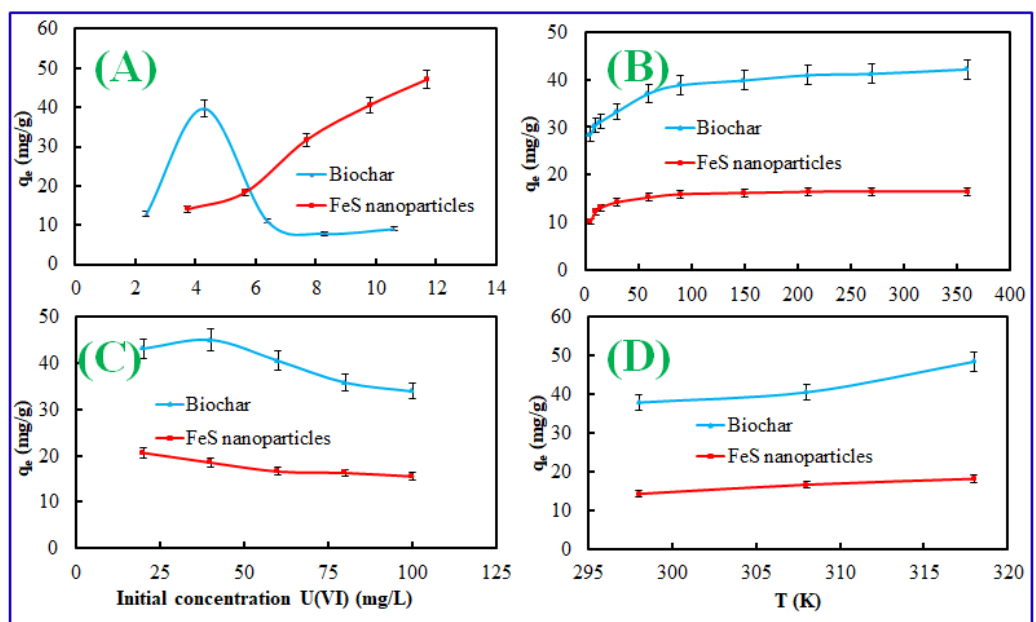

Fig. 4: Effect of operation parameters on adsorption capacity by biochar and FeS nanoparticles (A: pH, B: contact time, C: initial concentration of $\mathrm{U}(\mathrm{VI}), \mathrm{D}:$ temperature). 
Effect of pH: pH in solution could affect the stability, surface potential and reactivity of biochar and FeS nanoparticles. Therefore, it was important to evaluate the effect of $\mathrm{pH}$. Experimental conditions were as following: Initial concentration U(VI) was $60 \mathrm{mg} / \mathrm{L}$, contact time was 360 min, dosage of biochar or FeS nanoparticle was $0.1 \mathrm{~g}$, and temperature was $308 \mathrm{~K}$. The initial $\mathrm{pH}$ in solution ranged from 2.0 to 12.0. Fig. 4A displayed the effect of initial $\mathrm{pH}$ in solution on the adsorption capacity of $\mathrm{U}(\mathrm{VI})$ by biochar and $\mathrm{FeS}$ nanoparticles. It suggested that the initial $\mathrm{pH}$ in solution influenced the adsorption capacity of U(VI) by biochar and FeS nanoparticles. It might be the reason that formation of $\mathrm{U}(\mathrm{VI})$ in solution varied with initial $\mathrm{pH}$ value in the solution. At alkaline $\mathrm{pH}$, the dominant $\mathrm{U}(\mathrm{VI})$ species shifted from positively charged $\left(\mathrm{UO}_{2}\right)_{3}(\mathrm{OH})_{5}{ }^{+}$and $\left(\mathrm{UO}_{2}\right)_{4}(\mathrm{OH})_{7}{ }^{+}$to negatively charged $\left(\mathrm{UO}_{2}\right)_{3}(\mathrm{OH})_{7}{ }^{-}, \mathrm{UO}_{2}(\mathrm{OH})_{3}{ }^{-}$and $\mathrm{UO}_{2}(\mathrm{OH})_{4}{ }^{2-}$ (Zhu et al. 2019). Therefore, the initial $\mathrm{pH}$ in solution was an important operation parameter for adsorption of U(VI) by biochar and $\mathrm{FeS}$ nanoparticles.

Effect of contact time: Experimental conditions were: initial concentration of $\mathrm{U}(\mathrm{VI})$ was $60 \mathrm{mg} / \mathrm{L}$, $\mathrm{pH}$ was 4.5 , the dosage of biochar or FeS nanoparticle was $0.1 \mathrm{~g}$ and temperature was $308 \mathrm{~K}$. The contact time was 5, 10, 15, 30, 60, 90, 150, 210, 270 and $360 \mathrm{~min}$, respectively. Fig. 4B described the effect of contact time on the adsorption capacity of $\mathrm{U}(\mathrm{VI})$ ions in solution by biochar and FeS nanoparticles. As shown in Fig. $4 \mathrm{~B}$, the adsorption capacity of $\mathrm{U}(\mathrm{VI})$ increased quickly at the first stage. Then adsorption capacity of U(VI) increased slowly as the contact time increased. The adsorption capacity of U(VI) increased very less when the adsorption process reached adsorption equilibrium. For biochar and FeS nanoparticles, the adsorption equilibrium of contact time was 360 min. At the first stage, U(VI) could be very rapidly adsorbed by biochar or FeS nanoparticles because of many adsorption sites. As the initial concentration of U(VI) increased, adsorption sites were utilized fully and the adsorption process reached saturation gradually.

Effect of initial concentration U(VI): Experimental conditions were: contact time was $360 \mathrm{~min}, \mathrm{pH}$ was 4.5 , the dosage of biochar or $\mathrm{FeS}$ nanoparticle was $0.1 \mathrm{~g}$ and the temperature was $308 \mathrm{~K}$. The initial concentration U(VI) was 20, 40, 60, 80 and $100 \mathrm{mg} / \mathrm{L}$, respectively. The effect of initial concentration U(VI) on adsorption capacity of U(VI) by biochar and $\mathrm{FeS}$ nanoparticles is shown in Fig. 4C. It suggested that adsorption capacity decreased as the initial concentration $\mathrm{U}(\mathrm{VI})$ increased. When the initial concentration U(VI) was $100 \mathrm{mg} / \mathrm{L}$, the adsorption capacity for biochar and FeS nanoparticles reached 34.12 and $15.52 \mathrm{mg} / \mathrm{g}$, respectively. The adsorption capacity of biochar was better than that of FeS nanoparticles.
Effect of temperature: Experimental conditions were: initial concentration $\mathrm{U}(\mathrm{VI})$ was $60 \mathrm{mg} / \mathrm{L}$, $\mathrm{pH}$ was 4.5 , the dosage of biochar or FeS nanoparticle was $0.1 \mathrm{~g}$ and the contact time was $360 \mathrm{~min}$. The temperature was 298, 308 and 318 $\mathrm{K}$, respectively. It was found that the removal efficiency of U(VI) ion in aqueous solution increased with increasing solution temperature from $293 \mathrm{~K}$ to $313 \mathrm{~K}$. It also indicated that the adsorption process is endothermic. The enhancement in the adsorption capacity might be due to the chemical interaction between adsorbates and adsorbent, creation of some new adsorption sites or the increased rate of intraparticle diffusion of adsorbate molecules into the pores of biochar or FeS nanoparticles at higher temperatures (Cho et al. 2011, Nethaji et al. 2013).

\section{CONCLUSIONS}

The biochar from the peanut shell and FeS nanoparticles was prepared. The characteristics of biochar and $\mathrm{FeS}$ nanoparticles were determined by SEM, EDS, FT-IR and BET adsorption method. The adsorption capacity and influencing factors of $\mathrm{U}(\mathrm{VI})$ in aqueous solution by the biochar and FeS nanoparticles were studied in detail by the adsorption experiments. The experimental results showed that the influencing factors, such as contact time, $\mathrm{pH}$ in solution, initial concentration U(VI) and solution temperature, had an important influence on the adsorption capacity of U(VI) by biochar and FeS nanoparticles.

\section{ACKNOWLEDGMENTS}

The research was supported by Natural Science Foundation of Zhejiang Province, China (LGF19C030001 and LGF20C030001), Basic Public Welfare Research Project of Zhejiang Province (LGN20C150003) and the Key Research Program of Shaoxing University (2019LG1003).

\section{REFERENCES}

Ahmad, M., Rajapaksha, A.U., Lim, J.E., Zhang, M., Bolan, N., Mohan, D., Vithanage, M., Lee, S.S. and Ok, Y.S. 2014. Biochar as a sorbent for contaminant management in soil and water: a review. Chemosphere, 99: 19-33.

Cho, D.W., Chon, C.M., Kim, Y.J., Jeon, B.H., Schwartz, F.W., Lee, E.S. and Song H. 2011. Adsorption of nitrate and $\mathrm{Cr}$ (VI) by cationic polymer-modified granular activated carbon. Chem. Eng. J., 175: 298-305.

Decker, J.D., Folens, K., Clercq, J.D., Meledina, M., Tendeloo, G.V., Laing, G.D. and Voort, P.V.D. 2017. Ship-in-a-bottle CMPO in MIL$101(\mathrm{Cr})$ for selective uranium recovery from aqueous streams through adsorption. J. Hazard. Mater., 335: 1-9.

Feng, J., Zhu, B.W. and Lim, T.T. 2008. Reduction of chlorinated methanes with nano-scale Fe particles: effects of amphiphiles on the dechlorination reaction and two-parameter regression for kinetic prediction. Chemosphere, 73: 1817-1823. 
Feng, M.L., Sarma, D., Qi, X.H., Du, K.Z., Huang, X.Y. and Kanatzidis, M.G. 2016. Efficient removal and recovery of uranium by a layered organic-inorganic hybrid thiostannate. J. Am. Chem. Soc., 138: 12578-12585.

Hua, B. and Deng, B. 2008. Reductive immobilization of uranium(VI) by amorphous iron sulfide. Environ. Sci. Technol., 42: 8703-8708.

Hyun, S.P., Davis, J.A., Sun, K. and Hayes, K.F. 2012. Uranium (VI) reduction by iron(II) monosulfide mackinawite. Environ. Sci. Technol., 46: 3369-3376.

Jin, J., Li, S.W., Peng, X.Q., Liu, W., Zhang, C.L., Yang, Y., Han, L.F., Du, Z.W., Sun, K. and Wang, X.K. 2018. $\mathrm{HNO}_{3}$ modified biochars for uranium(VI) removal from aqueous solution. Biores. Technol., 256: $247-253$.

Liu, J., Valsaraj, K.T., Devai, I. and DeLaune, R. 2008. Immobilization of aqueous $\mathrm{Hg}$ (II) by mackinawite (FeS). J. Hazard. Mater., 157: 432-440.

Liu, M.X., Dong, F.Q., Yan, X.Y., Zeng, W.M., Hou, L.Y. and Pang, X.F. 2010. Biosorption of uranium by Saccharomyces cerevisiae and surface interaction under culture conditions. Biores. Technol., 101: 8573-8580.

Li, Z.D., Zhang, H.Q., Xiong, X.H. and Luo, F. 2019. U(VI) adsorption onto covalent organic frameworks-TpPa-1. J. Solid State Chem., 277: 484-492.

Li, Z.J., Chen, F., Yuan L.L., Zhao, Y.L., Chai, Z.F. and Shi, W.Q. 2012. Uranium(VI) adsorption on graphene oxide nanosheets from aqueous solution. Chem. Eng. J., 210: 539-546.

Lovering, J.R., Yip, A. and Nordhaus, T. 2016. Historical construction costs of global nuclear power reactors. Energy Policy, 91: 371-382.

Lyu, H.D., Tang, J.C., Huang, Y., Gai, L.S., Zeng, E.Y., Liber, K. and Gong, Y.Y. 2017. Removal of hexavalent chromium from aqueous solutions by a novel biochar supported nanoscale iron sulfide composite. Chem. Eng. J., 322: 516-524.

Ma, F.Q., Nian, J.R., Bi, C.L., Yang, M., Zhang, C.H., Liu, L.J., Dong, H.X., Zhu, M.X. and Dong, B. 2019. Preparation of carboxylated graphene oxide for enhanced adsorption of U(VI). J. Solid State Chem., 277: 9-16.

Maxim, I.B., Edward, J.O., Eric E.R., Jeremy, B.F. and Kenneth, M.K. 2007. Adsorption of $\mathrm{Fe}(\mathrm{II})$ and U(VI) to carboxyl-functionalized microspheres: The influence of speciation on uranyl reduction studied by titration and XAFS. Geochim. Cosmochim. Ac., 71: 1898-1912.

Milad, M., Reza, T., Abolghasem, F. and Joel, T.M. 2018. Fe(III), Cu(II) and U(VI) binuclear complexes with a new isothiosemicarbazone ligand: Syntheses, characterization, crystal structures, thermal behavior and theoretical investigations. Inorg. Chim. Acta, 4821: 643-653.

Nethaji, S., Sivasamy, S. A. and Mandal, A.B. 2013. Preparation and characterization of corn cob activated carbon coated with nano-sized magnetite particles for the removal of $\mathrm{Cr}(\mathrm{VI})$. Biores. Technol., 134: 94-100.

Qiu, M.Q. and Huang, P. 2017. Kinetic and thermodynamic studies on the adsorption of zinc ions from aqueous solution by the blast furnace slag. Nature Environ. Poll. Technol., 16: 639-642.

Sun, Y.B., Zhang, R., Ding, C.C., Wang, X.X., Cheng, W.C., Chen, C.L. and Wang, X.K. 2016. Adsorption of U(VI) on sericite in the presence of Bacillus subtilis: A combined batch, EXAFS and modeling techniques. Geochim. Cosmochim. Ac., 180: 51-65.

Veliscek-Carolan, J. 2016. Separation of actinides from spent nuclear fuel: A review. J. Hazard. Mater., 318: 266-281.

Vogel, M., Günher, A., Rossberg, A., Li, B., Bernhard, G. and Raff, J. 2010. Biosorption of U(VI) by the green algae Chlorella vulgaris in dependence of $\mathrm{pH}$ value and cell activity. Sci. Total Environ., 409: 384-395.

Zhu, W., Lei, J., Li, Y., Dai, L., Chen, T., Bai, X., Zhou, J., Wang, L. and Duan, T. 2019. Procedural growth of fungal hyphae/ $\mathrm{Fe}_{3} \mathrm{O}_{4} /$ graphene oxide as ordered-structure composites for water purification. Chem. Eng. J., 355: 777-783. 